\title{
The Evaluation of Saravan Fault Activities in Iran on the Basis of Geomorphologic Evidences
}

\author{
Mohsen Jami ${ }^{1 *}$, Elahe javadi mousavi ${ }^{2}$, Atieh Hadizadeh ${ }^{3}$ and Mohsen Pourkermani ${ }^{4}$ \\ 1,2,3,4 Science and Research Branch, Islamic Azad University, \\ Department of Geology, Tehran- Iran; mohsenjami84@yahoo.com
}

\begin{abstract}
Saravan fault in Iran is a reverse fault with the dextral strike- slip component. In this paper, we studied the Current Activity Effects of this fault on Regional Structural Geomorphology. This study includes not only the new Neotectonic evidences but also parameters such as mountain front sinuosity 1, rate index (V) , Hydraulic Gradient Index of Stream (SL) that has carried out by field sampling, using satellite images, topographic maps and SRTM data. The mean calculated values from geomorphologic indices of meanders of mountain front, the ratio of valley bottom over its height and the ratio of $\mathrm{V}$ are 1.76, 0.98, and 0.77, respectively. These values indicate the high tectonic activities in Saravan region. The existence of Geomorphologic Evidences such as moved channels has proved Dextral Fault for the youngest stage of performance called Post-Cenozoic. It is found by the study of regional morph tectonic units such that the whole region is active tectonically, and Saravan fault where located in the middle part has higher activity than its two northwestern and southeastern extremes.
\end{abstract}

Keywords: Saravan Fault, Iran, Morphtectonic, Geotectonic.

\section{Introduction}

The Saravan fault is located in southeastern of Iran, $27^{\circ}$ to $28^{\circ}$ latitudinally and $61^{\circ}$ and $30^{\prime}$ to $62^{\circ}$ and $45^{\prime}$ longitudinally, that has been covered by Geological Map 1:250000 of Saravan. In Iran Geotectonic Division, Saravan fault and range of its performance are located in the suture zone and the east Flysch of Iran. The most stones of this region are Flysch of Eocene. This fault where extended from southern range of eastern - northeastern Saravan Mountains and it is $270 \mathrm{~km}$ in length and it has been separated $\mathrm{Ba}$ Damo-Siyahan Stratigraphy from Saravan. [1].

The most part of the fault (all over Saravan plain) has been extended N50W generally and about 50 kilometers of the eastern fault (spacing of Dehak village to Pakistan border) has been also extended along east to west. It is found that the main process of these structures such as the main faults and the axis of folds and so on have been extended from northwestern to southeastern, i.e. N130- 140.
Morphotectonic Analysis Method that used to interpret Geological Structures has been derived from Topographic and telemetric data. Theses analyses considers spatial relations between landforms and tectonic processes that created them and Morphotectonic inferences are in direction of dynamic or kinetic analysis of these processes.

\section{The Study of Geomorphologic Indices}

Some quantitative indices has been considered to evaluate the ratio of regional geotectonic activities, these indices indicate movement and the lifting-up one block than other block along the fault and the morphotectonic indications resulted from reversed and extensive movements.

In this study, it has been considered not only the new Neotectonic evidences but also parameters such as mountain front sinuosity 1 , rate index $(\mathrm{V})$, Hydraulic Gradient

* Corresponding author:

Mohsen Jami (mohsenjami84@yahoo.com) 
Index of Stream (SL) that has carried out by field sampling, using satellite images, topographic maps and SRTM data.

\section{The Mountain Front Sinuosity}

In fact, this index indicates the relationship between tendency of rivers to produce irregular front and vertical tectonic activity to produce a straight front on the mountain that surface processes lead to be irregularity of mountain front and morphotectonic processes lead to be these fronts smoother and linear. On the basis of resulted calculation, the range of changes is a value higher than 1 in SMF index.[3]

$$
\text { Equation: } \mathrm{Smf}=\mathrm{Lmf} / \mathrm{Ls}
$$

If the ratio of this index is equal to 1 , it indicates the activity of geotectonic processes and the youth of mountains, and the increase of this value indicates lesser tectonic activities and the dominance of surface processes. In following relation, $\mathrm{Lmf}$ value is the length of the mountain meander and Ls is the length of the straight line of the mountain front.

According to the above mentioned features, the mountain front along Saravan fault is divided into 20 fronts to obtain Smf index (Figure 1\& 2) and then it was calculated from the north to the south for different blocks.

By studying these mountain fronts parallel to the fault, it can be determined relative intensity of tectonic activities and also the regions where have the highest lifting-up activ-

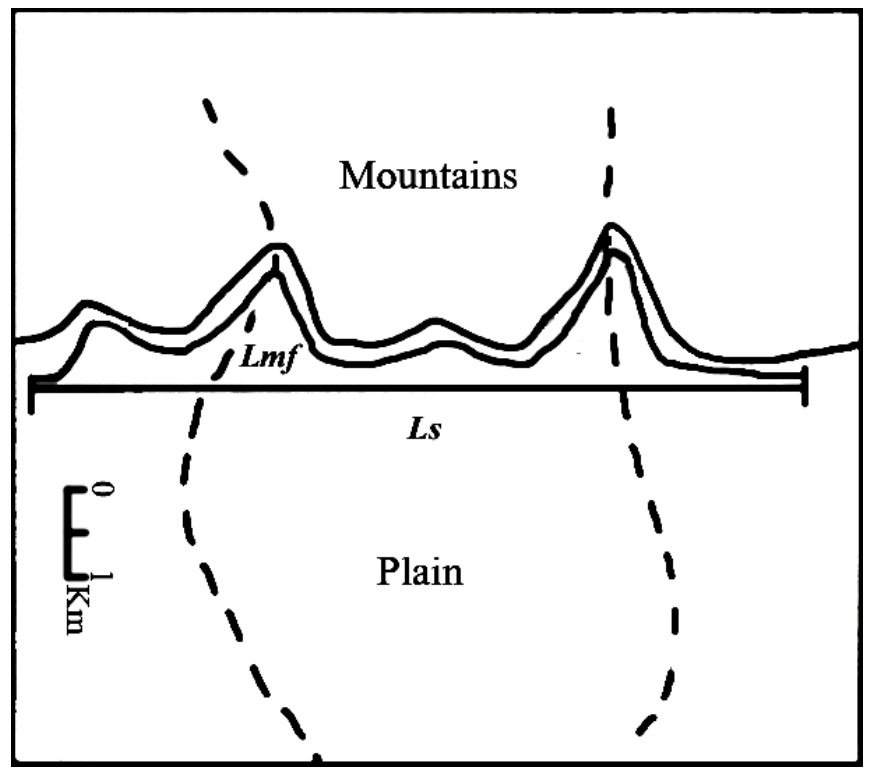

Figure 1. Method of calculating SMF index.

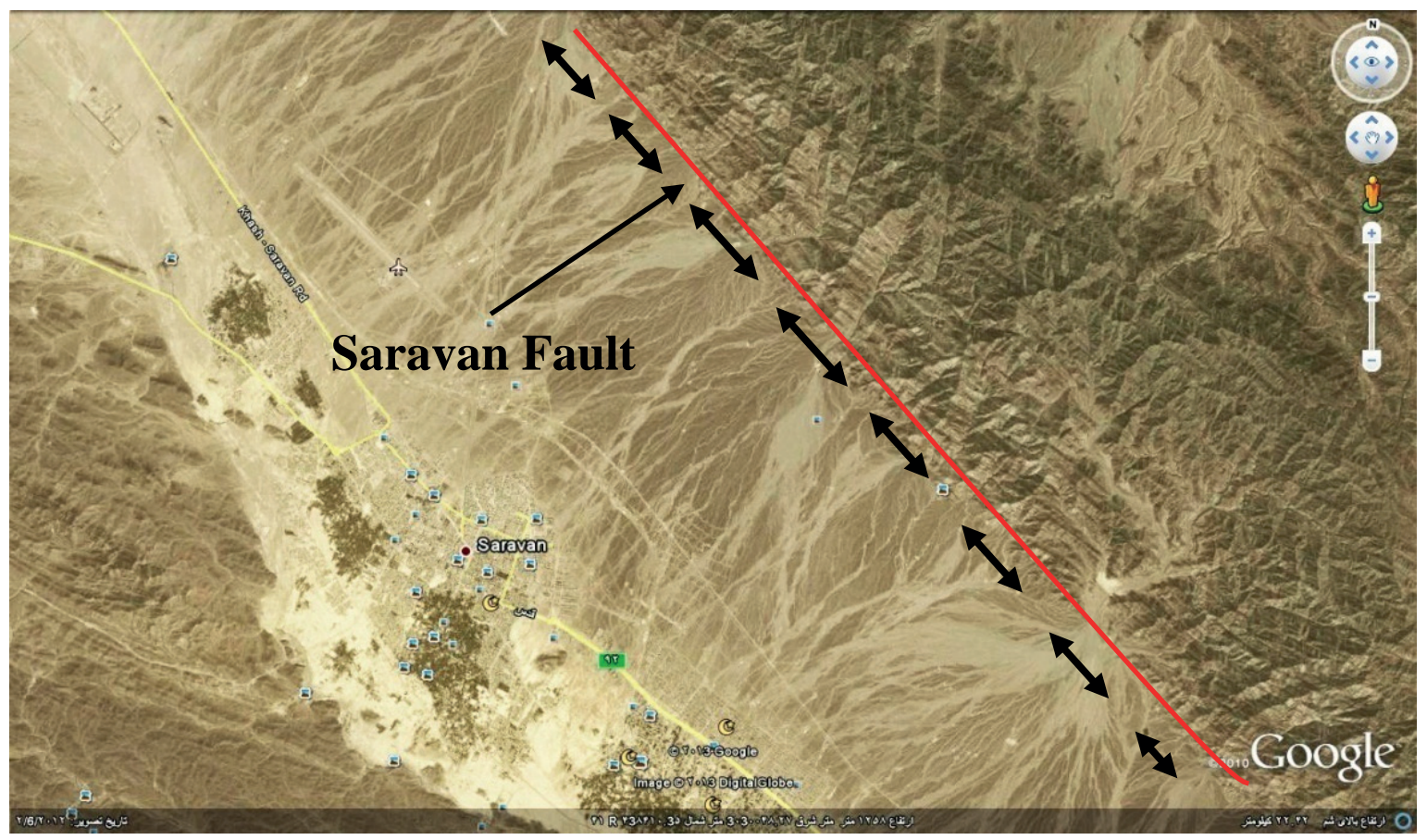

Figure 2. Calculation of Smf Index, Measurement Direction is from Northwest to Southeast. 
ities. Then, by comparing it with the other morphometric indices, it can be obtained the final sum up of the condition of activities and active regions along the Saravan fault (Table 1).

As it is shown in Table 1, the calculated values of Smf index are small (lower than 2) for the most regions and it indicates that there is a relatively high activity in all over Saravan fault. In some regions, the considered mountain fronts have the least curve and sinuosity then their Smf index is the least.

Since it can't be expressed any idea about regional tectonic based upon one morphotectonic index, thus other indices were also studied and finally the regional tectonic activities are determined according to all indices.

Table 1. The derived numbers for Smf index in 24 blocks of Saravan Fault

\begin{tabular}{cccccccc}
\hline Front & Ls & Lmf & Smf & Front & Ls & Lmf & Smf \\
\hline 1 & 3.4 & 5.4 & 1.6 & 11 & 7.4 & 12 & 1.6 \\
2 & 5.6 & 8.7 & 1.5 & 12 & 6.5 & 10.6 & 1.6 \\
3 & 6.5 & 9.1 & 1.4 & 13 & 5.7 & 8.7 & 1.5 \\
4 & 5.3 & 9.5 & 1.8 & 14 & 6.06 & 8.3 & 1.4 \\
5 & 5.1 & 8.2 & 1.6 & 15 & 5.9 & 9.4 & 1.6 \\
6 & 5.9 & 7.7 & 1.3 & 16 & 4.5 & 6.4 & 1.4 \\
7 & 5.5 & 6.8 & 1.2 & 17 & 4.9 & 5.8 & 1.2 \\
8 & 5.6 & 8.5 & 1.5 & 18 & 5.2 & 8.5 & 1.6 \\
9 & 3.7 & 7.5 & 2 & 19 & 4.1 & 6.8 & 1.6 \\
10 & 5.9 & 8.5 & 1.4 & 20 & 4.4 & 7.3 & 1.7 \\
\hline
\end{tabular}

\section{Truncated Percentage Index (Cleaved) of Mountain Front (Facet \%)}

Facet is defined as triangular or polygonal morphology which is created between the interfaces of two channels resulting from erosion (Figure 3). The percentage of Facet in mountain front or $\mathrm{F} \%$ is another quantitative index to determine relative geotectonic activity of a mountain front which consists of the ratio of the total length of facets in a mountain front (Lmfd) to the length of straight line against it (Ls). A mountain front is considered truncated if it includes several definite and significant channels, and divided it into distinct facets and clearly causes to deviat the contour lines in the topographic maps. Some of the facets might have been eroded by channels which cause to be irregularity of its morphology that it is found in the maps and images. More active Mountain fronts have less truncation and appear as a continuous mountainous front with great and definite facets that have little internal truncation. [3].

The percentage of truncation or F\% has been approximated $100 \%$ in the active mountain fronts which it also reduces by decreasing the activity. This index is ranged $0-100 \%$ (Table 2). The mountain along Saravan fault was divided into 28 blocks to obtain faceting index (F \%) and then this index was calculated for different blocks from north to south.

Most active regions based on these calculations are located on the middle part of Saravan Fault. It means that the least faceting of mountain front has been created by current streams in the region. But the southern and

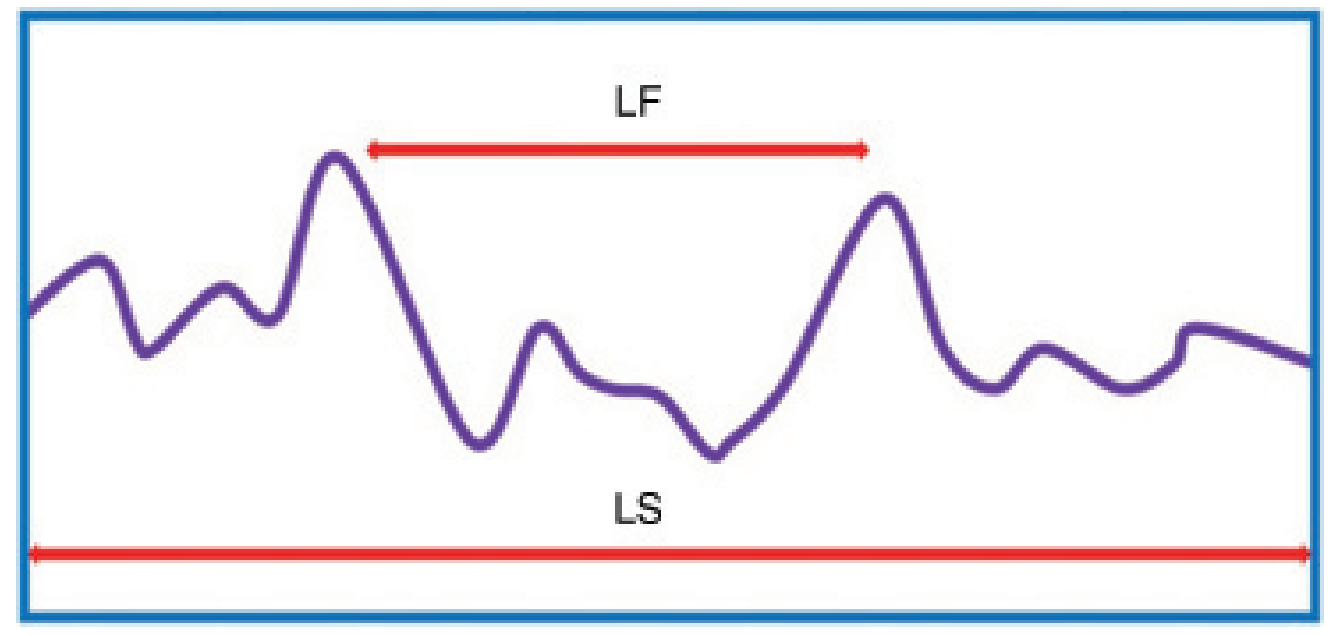

Figure 3. Method of calculating Facet Index. 
Table 2. The obtained numbers for index F\% in 28 blocks of Saravan Fault

\begin{tabular}{cllccccc}
\hline Front & Ls & Lf & F\% & Front & Ls & Lf & F\% \\
\hline 1 & 3.847 & 2.02 & $\mathbf{5 2}$ & 11 & 8.3 & 6.7 & $\mathbf{8 1}$ \\
2 & 4.5 & 3.06 & $\mathbf{6 6}$ & 12 & 7.5 & 4.9 & $\mathbf{6 4}$ \\
3 & 6.2 & 4.37 & $\mathbf{6 9}$ & 13 & 5.7 & 4.5 & $\mathbf{7 9}$ \\
4 & 5.7 & 4.41 & $\mathbf{7 7}$ & 14 & 6.06 & 5.08 & $\mathbf{8 3}$ \\
5 & 6.1 & 5.9 & $\mathbf{9 7}$ & 15 & 5.9 & 3.9 & $\mathbf{4 4}$ \\
6 & 6.08 & 5.1 & $\mathbf{8 5}$ & 16 & 4.5 & 3.5 & $\mathbf{7 7}$ \\
7 & 5.7 & 3.8 & $\mathbf{6 7}$ & 17 & 4.9 & 3.8 & $\mathbf{7 7}$ \\
8 & 5.7 & 4.8 & $\mathbf{8 4}$ & 18 & 5.2 & 3.4 & $\mathbf{6 5}$ \\
9 & 4.6 & 3.4 & $\mathbf{7 4}$ & 19 & 4.1 & 2.3 & $\mathbf{5 5}$ \\
10 & 6.05 & 3.9 & $\mathbf{6 4}$ & 20 & 4.4 & 3.1 & $\mathbf{7 0}$ \\
\hline
\end{tabular}

northern regions of Saravan Fault have lesser values of F \% and according to this index; the level of relative lifting-up activity is less. These results are similar to the results of mountain front sinuosity significantly.

\section{Length - Gradient Stream Index (SL)}

Stream gradient index is one of the indices to evaluate active tectonic in relation to the shape of stream channels that defined with the following equation:

$$
\mathrm{SL}=(\Delta \mathrm{H} / \Delta \mathrm{L} \times \mathrm{L})
$$

Where $\Delta \mathrm{H} / \Delta \mathrm{L}$ is local stream gradient $(\Delta \mathrm{H}$ is height differential of the range and $\Delta \mathrm{L}$ is the range length) and (L) is channel length from the straight stream line to the center that its gradient is calculated or in other words, $(\mathrm{L})$ is the total channel length from the point which index is calculated (Figure 4) to the highest channel point [3]. SL index in different parts of fault has been studied for 10 basins. The given index shows different SL values in different parts of the fault which are given in the rows 1-10 of Table 3. The obtained results represent that the fault is active.

Table 3 shows the obtained values of SL for the important streams that passes through Saravan fault, therefore are affected by its tectonic movements. As a whole, SL values have a different shifting range on the basis of structural geotectonic activity and its position in a structural state, topographic status, rate of flow and the lithologic type. The SL values have significant numerical differences as compared with each other. Because the value of SL difference can be unexpected in different streams regarding some parameters such as stream length. It can be also observed that streams 4 and 9 where located in the middle part of Saravan fault have high SL index. Therefore, it can be said that geotectonic movements, especially lifting-up movements have increased the stream gradient. As well, an important factor such as lithologic matter can be also influenced on the SL value. Hence, more resistant lithology, more SL value and less resistant lithology, less SL value.

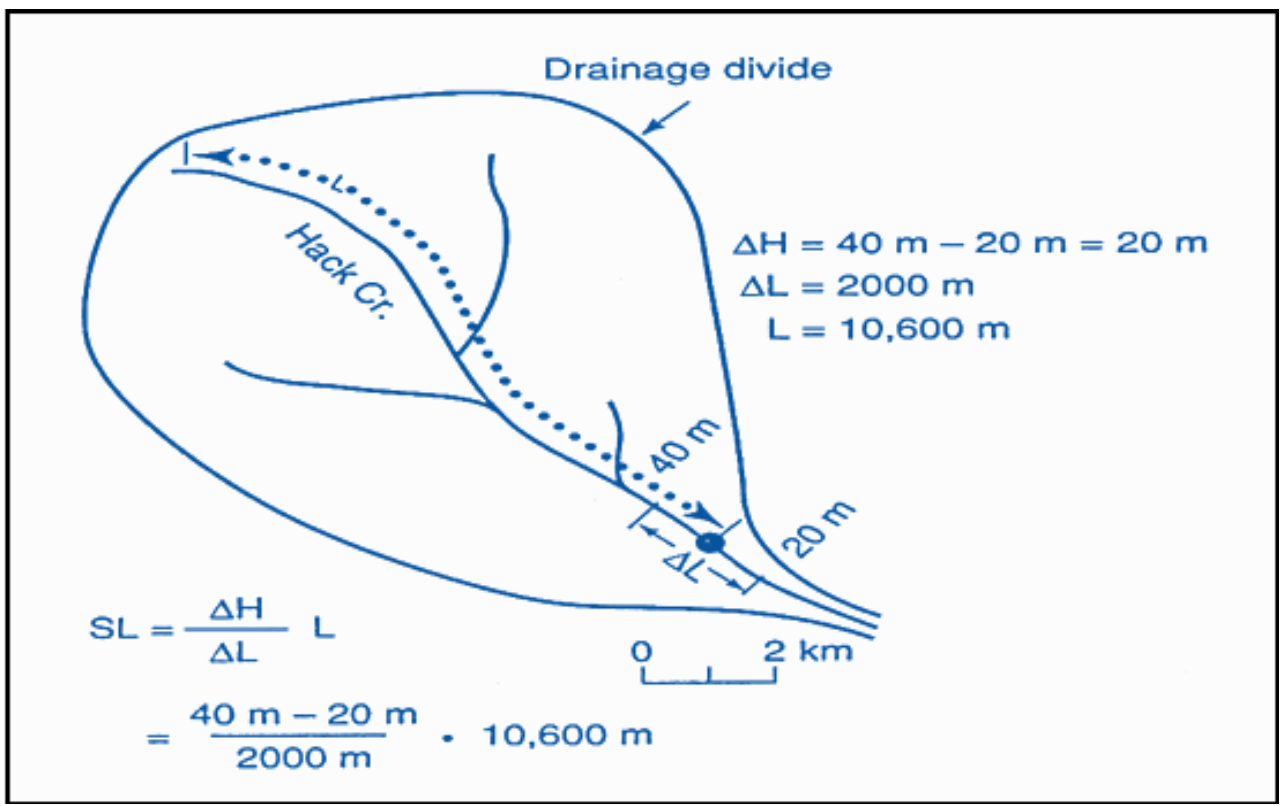

Figure 4. Method of calculating SL index. 
Table 3. The obtained numbers for SL index

\begin{tabular}{lccc}
\hline Number & SL & Number & SL \\
\hline 1 & $\mathbf{1 0 2}$ & 6 & $\mathbf{1 5 5}$ \\
2 & $\mathbf{2 1 2}$ & 7 & $\mathbf{9 8}$ \\
3 & 36 & 8 & $\mathbf{1 6 5}$ \\
4 & $\mathbf{2 8 6}$ & 9 & $\mathbf{3 4 0}$ \\
5 & $\mathbf{3 1 2}$ & 10 & $\mathbf{2 3 6}$ \\
\hline
\end{tabular}

\section{Ratio Index V}

$\mathrm{V}$ ratio index represents a relation between the width of valley bottom near to the mountain front and the mean height of its top chords that can be calculated the ratio of tectonic activities and regional erosion relatively and $\mathrm{V}$ ratio can be obtained by using this method (Figure 5) as following:

Equation 1-1

$$
\mathrm{V}=\mathrm{AV} / \mathrm{AC}
$$

This ratio gives us information about regional lifting-up so that if its value is about 1 , the valley is $U$ shape or if the value is very small, the valley is $\mathrm{V}$ shape that can indicate the vertical performance of active tectonics. The values more than 1 represent that the width of the valley is higher than its depth and regional tectonic activities has been approximately stopped.

The measured values of $\mathrm{V}$ index are shown for the case study of region in (Table 4 ).

According to the above table, the least value of $\mathrm{V}$ ratio is related to Saravan regions and zarawy and sheikh Rostam villages. In the regions with high $\mathrm{V}$ ratio, Meander streams are flowing and in the regions with low $\mathrm{V}$ ratio, the streams are flowing in strength with less width.

\section{Asymmetry Index of Drainage Basin (T)}

Another quantitative index is Diagonal Topographic Symmetrical Factor (T) to estimate asymmetry of basin.

$$
\mathrm{T}=\mathrm{Da} \cdot \mathrm{Dd}
$$

Where $\mathrm{Da}$ is the distance from the midline of the drainage basin to the midline of active meander belt and Dd is the distance from the midline of the basin to the dividing line of the basin. (Figure 6)

For a basin which is completely symmetrical, $\mathrm{T}$ is equal to 0 . As the asymmetry increases, $t$ value also increases and approaches 1 . Supposing that the bedrock gradient

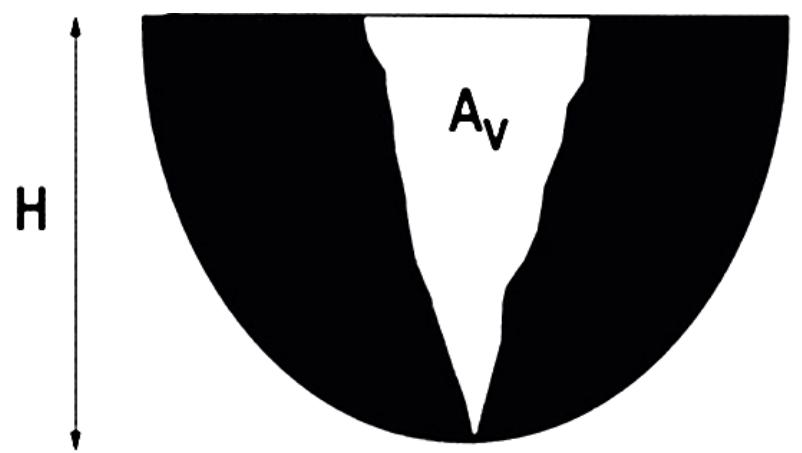

Figure 5. Indicates the method of calculating parameter of $\mathrm{V}$ ratio.

Table 4. The values of $\mathrm{V}$ index along Sravan Fault

\begin{tabular}{cccc}
\hline Zone & AC $(\mathrm{m} 2)$ & Av $(\mathrm{m} 2)$ & Vr \\
\hline 1 & 44410 & 54070 & 0.8 \\
2 & 25060 & 34860 & 0.7 \\
3 & 21510 & 35200 & 0.62 \\
4 & 29430 & 43220 & 0.68 \\
5 & 32460 & 49340 & 0.65 \\
6 & 50560 & 64760 & 0.78 \\
7 & 63520 & 62760 & 1.1 \\
& 23250 & 33110 & 0.7 \\
& 44350 & 44390 & 1 \\
8 & 47010 & 60570 & 0.77 \\
& 35630 & 44930 & 0.8 \\
\hline
\end{tabular}

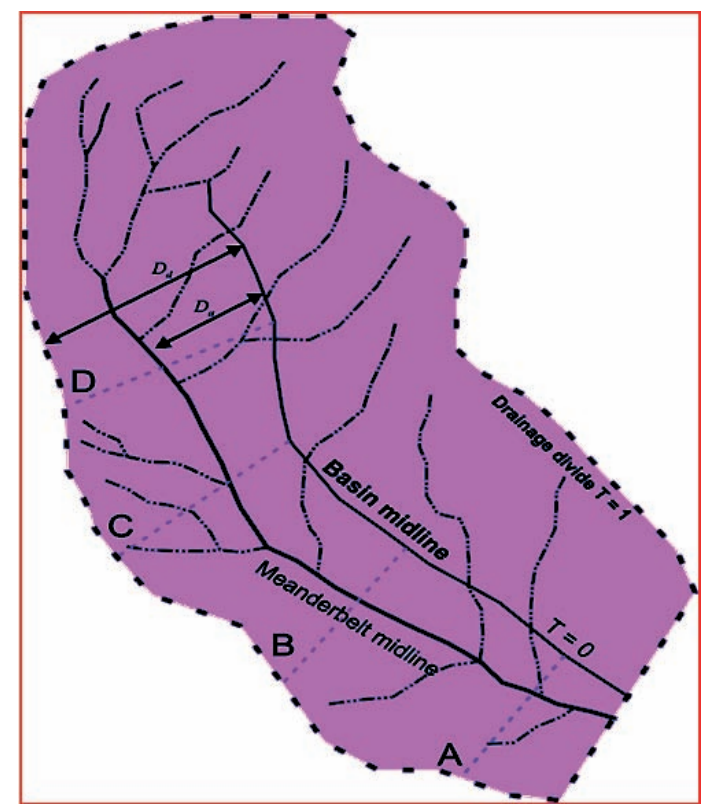

Figure 6. Ideal diagram to calculate Topographic Symmetrical Factor T. 
Table 5. Obtained results of calculation $\mathrm{T}$

\begin{tabular}{lcccll}
\hline Basin & T1 & T2 & T3 & T4 & \multicolumn{1}{c}{ Av } \\
\hline 1 & 0.58 & 0.47 & 0.59 & 0.49 & 0.5325 \\
2 & 0.55 & 0.24 & 0.44 & 0.41 & 0.41 \\
3 & 0.61 & 0.35 & 0.45 & 0.5 & 0.4775 \\
4 & 0.33 & 0.5 & 0.58 & 0.57 & 0.495 \\
5 & 0.52 & 0.68 & 0.68 & 0.53 & 0.6025 \\
6 & 0.61 & 0.7 & 0.55 & 0.6 & 0.615 \\
\hline
\end{tabular}

has influenced less on the migration of stream channels, then the direction of local migration is as a sign of distorting the earth. Therefore, $\mathrm{T}$ is an directed vector that its range changes from 0 to 1 .To calculate asymmetry index of the basin, namely, $\mathrm{T}$ index, at first it should be drawn an approximate symmetry line for every basin and vertical line on the main basin is drawn in several parts, then asymmetry index of the basin has been calculated by calculating the distance of main channel from the basin wall and also distance from assumed symmetry line. The index is examined locally for each basin by considering the present morphology in the region. (Table 5)

It is necessary to remind that $\mathrm{T}$ index is concluded well to justify tectonically when the secondary factors such as lithology, Type of folding and layering are less effective in the region.

\section{Conclusion}

The studying of regional morphotectonic units indicate that the whole region is active tectonically and regarding to the studies, Saravan fault has more activity in the middle part than its two northwestern and southeastern extremes. The mean calculated values of geotectonic indices of mountain front sinuosity, the ratio of the valley bottom on its height and the $\mathrm{V}$ ratio are 76.1, 0.98 and 77, respectively. These values indicate high tectonic activity in Saravan region.

\section{References}

1. Aqanbaty A (2004). Geological Survey of Iran, Geological and Mineral Exploration.

2. Berberian M, Qarshi $M$ et al. (1992). Research and Neotectonics, seismotectonics and seismic hazard - big and faulting in the expanse around Qazvin, Geological and Mineral Exploration country report No. 61, 1990.

3. PourKermani M, and solgi A (2009). Morphotectonic, Copyright MIT., Islamic Azad University, Tehran, Iran.

4. PourKermani M, and Arian M (2001). Structural geomorphology of northeastern Kurdistan, Sistan and Baluchestan University Journal of Humanities. Seventh year. No. 16.

5. Sadat M A A (1993). Tectonic map of Iran, published by the Geological Survey.

6. Bull W B, and Mcfadden L D, Tectonic geomorphology north and south of the Garlok fault, California. 8th Annual geomorphology sym., New York. at Bingamton, 1977 Enertec, Saveh site confirmation studies, preliminary report, phase 1B investigation. Volume 1: geology and seismology. Atomic Energy Organization of Iran, Tehran, 1978. 